Article

\title{
Evapotranspiration Estimation with UAVs in Agriculture: A Review
}

\author{
Haoyu Niu ${ }^{1, t, * \mathbb{D}}$, Tiebiao Zhao ${ }^{1}$, Dong Wang ${ }^{2}$ and YangQuan Chen ${ }^{1}$ \\ 1 University of California, Merced; hniu2@ucmerced.edu \\ 2 USDA-ARS Water Management Research Unit, San Joaquin Valley Agricultural Sciences Center, Parlier, \\ California, USA, 93648 \\ * Correspondence: hniu2@ucmerced.edu; Tel.: +1-530-566-6577 \\ + Current address: Room 22, 4225 Hospital Road, Atwater, California, 95301, USA
}

\begin{abstract}
Estimating evapotranspiration (ET) has been one of the most important research in agriculture recently because of water scarcity, growing population, and climate change. ET is the sum of evaporation from the soil and transpiration from the crops to the atmosphere. The accurate estimation and mapping of ET are necessary for crop water management. Traditionally, people use weighing lysimeters, Bowen ratio, eddy covariance and many other methods to estimate ET. However, these ET methods are points or location-specific measurements and cannot be extended to a large scale of ET estimation. With the advent of satellites technology, remote sensing images can provide spatially distributed measurements. The satellites multispectral images spatial resolution, however, is in the range of meters, which is often not enough for crops with clumped canopy structure such as trees and vines. And, the timing or frequency of satellites overpass is not always enough to meet the research or water management needs. The Unmanned Aerial Vehicles (UAVs), commonly referred to as drones, can help solve these spatial and temporal challenges. Lightweight cameras and sensors can be mounted on drones and take high-resolution images on a large scale of field. Compared with satellites images, the spatial resolution of UAVs' images can be as high as $1 \mathrm{~cm}$ per pixel. And, people can fly a drone at any time if the weather condition is good. Cloud cover is less of a concern than satellite remote sensing. Both temporal and spatial resolution is highly improved by drones. In this paper, a review of different UAVs based approaches of ET estimations are presented. Different modified models used by UAVs, such as Mapping Evapotranspiration at high Resolution with Internalized Calibration (METRIC), Two-source energy balance (TSEB) model, etc, are also discussed.
\end{abstract}

Keywords: Clumped canopy; evapotranspiration; Unmanned aerial vehicles; METRIC; remote sensing;

\section{Introduction}

Evapotranspiration (ET) estimation is important in precision agriculture water management. ET is known as the main outgoing water flux from the surface on the earth [1]. Mapping the ET temporally and spatially can be useful for evaluating soil moisture [2], drought monitoring [3], assessing crop water stress [4], etc. It is important to accurately quantify the ET in order to get a better understanding of crop growth. Estimating the ET accurately can also benefit the water resources management and weather forecast [5]. ET is a combination of two separate processes, the evaporation and the transpiration. Evaporation is the process whereby liquid water is converted to water vapour [6]. Then, the water vapour removes from the evaporating surface. Transpiration is the process of the vaporization of liquid water contained in plant tissues and the vapour removal to the atmosphere [6]. The current theory for transpiration is by the following three steps. First, the conversion of liquid phase water to vapor water, the side effect is to cause canopy cooling from latent heat exchange thus canopy temperature can be used as an indicator of ET. Second, diffusion of water molecules from 
inside plant stomata on the leaves to the surrounding atmosphere. Third, atmospheric air mixing by convection or diffusion can transport vapor near the plant surfaces to the upper atmosphere or off site away from the plant canopy. Usually, evaporation and transpiration occur simultaneously.

To estimate ET, there are direct and indirect methods. For direct methods, there are lysimeters [7] and water balance methods [8]

$$
W B=P+I-D-R-S=E T,
$$

where $W B\left(\mathrm{~mm} \mathrm{day}^{-1}\right)$ is water balance and $P\left(\mathrm{~mm} \mathrm{day}^{-1}\right)$ means precipitation. $I\left(\mathrm{~mm} \mathrm{day}^{-1}\right)$ is irrigation, $D\left(\mathrm{~mm} \mathrm{day}^{-1}\right)$ means drainage, $R\left(\mathrm{~mm} \mathrm{day}^{-1}\right)$ is runoff. $\mathrm{S}\left(\mathrm{mm} \mathrm{day}^{-1}\right)$ is the soil moisture storage. ET $\left(\mathrm{mm} \mathrm{day}^{-1}\right)$ is the evapotranspiration of the plant. However, these ET methods are usually point or location-specific measurements and cannot be extended to a large scale of ET estimation because of the heterogeneity of the land surface. And, the hydrologic processes can be very complex, too. Researchers sometimes also need to get variable land surface measurements and parameters [9], which is unlikely to get by these traditional methods. The experiment equipment is also very expensive, such as lysimeter, which is only available for a small group of people.

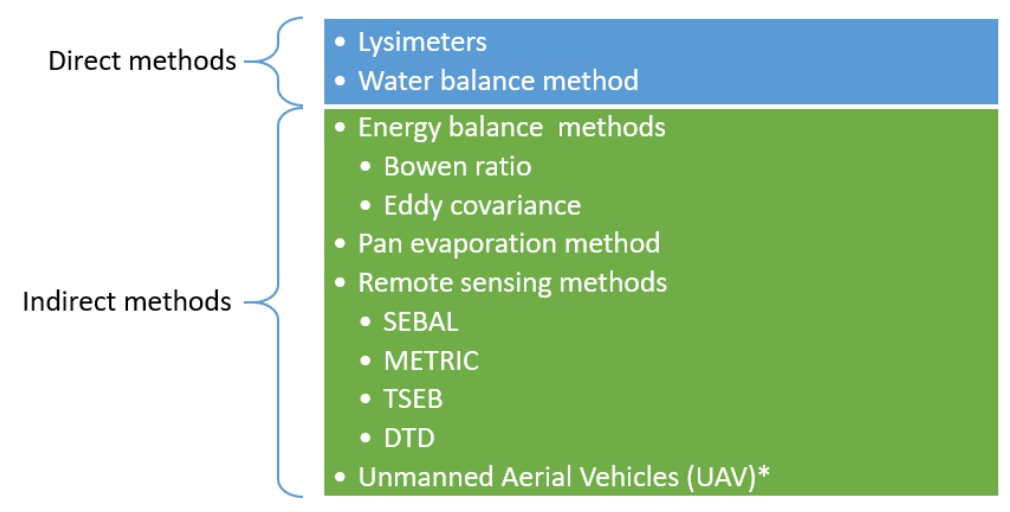

Figure 1. The direct and indirect methods for ET estimation

For indirect methods, there are energy balance methods [1], Pan evaporation methods [8] [10], and remote sensing methods [11]. For energy balance methods, Bowen ratio [12] [13] and eddy covariance [14] have been widely used in ET estimation. Over the past decades, remote sensing techniques have been considered as one of the most powerful methods for mapping and estimating ET [15] [16]. Because they can detect variations in vegetation and soil condition over space and time, remote sensing energy balance models have been useful to account for the spatial variability of ET at regional scales when using satellite platforms such as Landsat and ASTER [17] [18] [19] [20] [21]. Related research has been reviewed a few times [22] [23] [24]. Remote sensing techniques can provide information about Normalized Difference Vegetation Index (NDVI), Leaf Area index (LAI), surface temperature, surface albedo and so on. Several remote sensing models have been developed over the past decades, such as Surface Energy Balance Algorithm for Land (SEBAL) [18] [11], Mapping Evapotranspiration with Internalized Calibration (METRIC) [25], the Dual Temperature Difference (DTD) [26], and the Priestley-Taylor TSEB (TSEB-PT) [27]. There are mainly four energy fluxes in these remote sensing energy balance models, which are net radiation $R_{n}$, soil heat flux $G$, latent heat flux $L E$ and sensible heat flux $H$. Satellites images can help researchers get spatially distributed measurements, though, the resolution for those images are usually $30 \mathrm{~m}$, which are not good enough for many precision agriculture or ecological applications. Second, the timing of satellites overpass is not always synchronous with research requirements, they usually have a two-week revisit cycle [28]. Third, obtaining high-resolution images can be very expensive [21]. All these disadvantages limit the ET estimation by using traditional satellites images. 
As a new potential remote sensing platform, researchers are more and more interested in the potential of UAV data not only in precision agriculture, but also in different scientific and commercial communities [29] [30] [31] [32]. Drones can overcome some of those remote sensing limitations. For example, satellite remote sensing is prone to cloud cover, drones are below the clouds. Compared with satellites, UAVs can be operated at any time if the weather is good. Satellite has fixed flight path, drones are more mobile and more adaptive for site selection. And most drones are cost-effective (thousands of dollars). Mounted on the UAVs, light weight sensors, such as RGB cameras, multispectral cameras, and thermal infrared cameras, can help get higher resolution images. And, higher resolution images are important for recognizing the temporal and spatial variability related to the crops. UAVs have already been widely and successfully used in other agriculture research, such as water stress [33], tree canopy segmentation [34], counting watermelons [35]. Therefore, UAVs have great potential to help estimate ET. Many researchers have already been using UAVs for ET estimation. For example, in [36], the author implemented a remote sensing energy balance (RSEB) algorithms for estimating energy components, such as incoming solar radiation, sensible heat flux, soil heat flux and latent heat flux. Optical sensors were mounted on a UAV to provide high spatial resolution images. By using the UAV platform, experiments results show that the RSEB algorithm can estimate latent heat flux and sensible heat flux with errors of $7 \%$ and $5 \%$ respectively. It demonstrates that UAV could be used as an excellent platform to evaluate spatial variability in the field.

The rest of the paper is organized as follows. Section II introduces different UAV types being used for ET estimation. Advantages and disadvantages are discussed for them. Several commonly used light weight sensors are also compared in this section. UAV path planning and image processing methods are presented in the second section, too. In section III, the ET estimation methods and models for UAVs agricultural application, such as Two source energy balance (TSEB) model and METRIC model, are discussed. In Section IV, different results of ET estimation methods and models are compared and discussed. Challenges and opportunities for UAVs are mentioned in the conclusion section.

\section{Materials and Methods}

\subsection{Unmanned aerial vehicles (UAV) and light weight sensors}

Many kinds of unmanned aerial vehicles are used on different research purposes for ET estimation. Typically, there are two different UAV platforms, fixed-wings, and quadcopter. Fixed-wings can usually fly longer and carry heavy sensors. It can usually fly about 2 hours, which is suitable for a large scale of field. Quadcopters can fly about 30 minutes, which is used for short flight mission in a small scale of field.

In [27], researchers used a fixed-wing UAV to collect thermal data to estimate ET with two source energy balance models. The drone has a 2.2-meter wing span, which can fly 25 minutes when carrying a 2-kilogram payload. The drone was flying at a height of 90 meters with a speed of $60 \mathrm{~km} / \mathrm{h}$, which could cover a $400 \mathrm{~m} \times 400 \mathrm{~m}$ area in one flight. The SkyCircuits ground control station is used to design the flight path and for flight inspection. To collect thermal data, they used an Optris PI $450 \mathrm{LW}$ infrared camera. Based on the specifications, this uncooled thermal camera has an accuracy of $\pm 2{ }^{\circ} \mathrm{C}$ or $\pm 2 \%$ when the ambient temperature is between $0{ }^{\circ} \mathrm{C}$ to $70{ }^{\circ} \mathrm{C}$. The thermal images have a spectral range of $7.9 \mu \mathrm{m}$ and and an optical resolution of $382 \times 288$ pixels.

In [37], multispectral and thermal images were collected by using an airborne digital system developed by Utah State University. The digital system was installed in a Cessna TU206 aircraft, which also has four ImperX Bobcat B8430 digital cameras. The spectral bands for these cameras are, Red $(0.645 \mu \mathrm{m}-0.655 \mu \mathrm{m})$, Green $(0.545 \mu \mathrm{m}-0.555 \mu \mathrm{m})$, Blue $(0.465 \mu \mathrm{m}-0.475 \mu \mathrm{m})$ and Near-infrared (NIR) $(0.780 \mu \mathrm{m}-0.820 \mu \mathrm{m})$. A ThermalCAM SC640 (FLIR Systems Inc.) is also mounted on the aircraft to collect thermal infrared (TIR) images, the wavelength range is $7.5 \mu \mathrm{m}-13 \mu \mathrm{m}$.

In [21], the author estimated evapotranspiration in a peach orchard by using very-high-resolution imagery from an UAV platform (S1000, DJI, Shenzhen, China). A TIR camera (A65, FLIR Systems Inc.) 
and a multispectral camera RedEdge M (MicaSense, Seattle, WA, USA) are also mounted on the drone. The thermal camera A65 has a spatial resolution of $640 \times 512$ pixels. It has a Field of View (FOV) of $25^{\circ}(\mathrm{H}) \times 20^{\circ}(\mathrm{V})$. The focal length for this TIR camera is $25 \mathrm{~mm}$. For the RedEdge, it has five different bands, Red $(668 \mathrm{~nm})$, Green $(560 \mathrm{~nm})$, Blue $(475 \mathrm{~nm})$, Red edge $(717 \mathrm{~nm})$ and Near-infrared $(840 \mathrm{~nm})$. RedEdge M has spatial resolution of $1280 \times 960$ pixels with a focal length of $5.5 \mathrm{~nm}$.

Quadcopters have been widely used in agricultural research, such as [34] [38], which promises a great potential in ET estimation. In [34], a quadcopter named Hover was used as the UAV platform to collect aerial images, as shown in Figure 2.

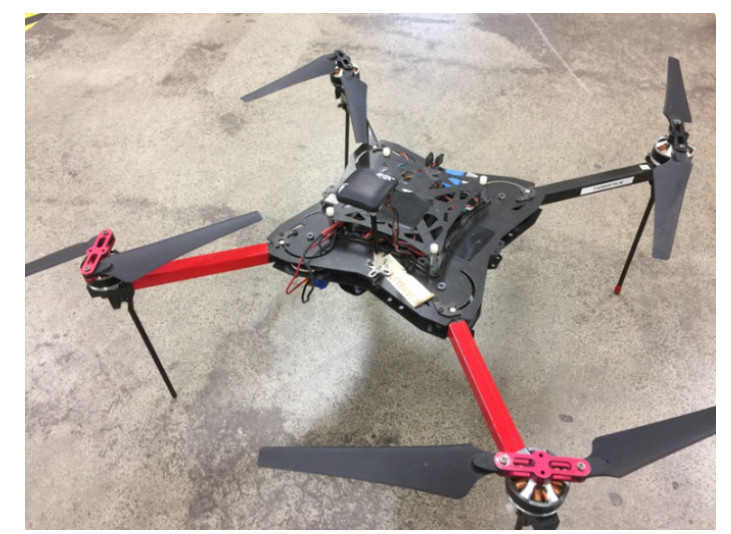

Figure 2. The Hover is equipped with a Pixhawk flight controller, GPS, telemetry antennas. Its lithium polymer battery has a capacity of $9500 \mathrm{mAh}$, which can support a 30-minute flight mission with a camera mounted on it.

The Hover was equipped with a Pixhawk flight controller, GPS, telemetry antennas. And, it can fly over the field by waypoints mode (designed by using Mission Planner software). The Hover's lithium polymer battery has a capacity of $9500 \mathrm{mAh}$, which can support a 30-minute flight mission with cameras mounted on the Hover drone.

To estimate ET, multispectral images can be collected by Survey 2 (MAPIR, USA) cameras with 4 bands, Blue, Green, Red (RGB) and Near-infrared (NIR). The MAPIR camera has a resolution of $4608 \times$ 3456 pixels, with a space resolution at $1.01 \mathrm{~cm} /$ pixel. The Survey 2 cameras have a faster interval timer, 2 seconds for JPG mode and 3 seconds for RAW + JPG mode. Faster interval timer would benefit the overlap design for UAV flight missions, such as reducing the flight time, enabling higher overlapping. Another multispectral camera being used is Rededge M (MicaSense, USA). The Rededge M has five bands, which are Blue, Green, Red, Near infrared, and Red edge. It has a resolution of $1280 \times 960$ pixel, with a $46^{\circ}$ field of view. With a Downwelling Light Sensor (DLS), which is a 5-band light sensor that connects to the camera, the Rededge $\mathrm{M}$ can measure the ambient light during a flight mission for each of the five bands. Then it can record the light information in the metadata of the images captured by the camera. After the camera calibration, the information detected by the DLS can be used to correct lighting changes during a flight, which usually happens because the clouds cover the sun during a UAV flight.

The thermal camera ICI 9640 P-Series (ICI, USA) was applied for collecting thermal images. The thermal camera has a resolution of $640 \times 480$ pixels. The spectral band is from $7 \mu \mathrm{m}$ to $14 \mu \mathrm{m}$. The dimension of the thermal camera is $34 \mathrm{~mm} \times 30 \mathrm{~mm} \times 34 \mathrm{~mm}$. The accuracy is supposed to be $\pm 2{ }^{\circ} \mathrm{C}$. A Raspberry Pi Model B computer was used to trigger the thermal cameras during the flight missions. The SWIR 640 P-Series, which is a shortwave infrared camera, can also be used for ET estimation. The spectral band is from $0.9 \mu \mathrm{m}$ to $1.7 \mu \mathrm{m}$. The accuracy for SWIR camera is $\pm 1^{\circ} \mathrm{C}$. It has a resolution of $640 \times 512$ pixels. 
Table 1. Some commonly used sensors on UAV platforms.

\begin{tabular}{cccc}
\hline Sensors & Function & Resolution & Accuracy \\
\hline Rededge M & Multispectral & $1280 \times 960$ pixels & $8.2 \mathrm{~cm} /$ pixel (per band) at $120 \mathrm{~m}$ \\
MAPIR Survey 2 & Multispectral & $4608 \times 3456$ pixels & $4.05 \mathrm{~cm} /$ pixel at $120 \mathrm{~m}$ \\
Mini MCA-6 & Multispectral & $1280 \times 1024$ pixels & $3.3 \mathrm{~cm} /$ pixel at $60 \mathrm{~m}$ \\
Sequoia & Multispectral & $4608 \times 3456$ pixels & $17 \mathrm{~cm} /$ pixel at $100 \mathrm{~m}$ \\
Cannon S 110 & Near infrared & $4000 \times 3000$ pixels & $3.5 \mathrm{~cm} /$ pixel at $100 \mathrm{~m}$ \\
ICI 9640 P & Thermal infrared & $640 \times 480$ pixel & $\pm 1{ }^{\circ} \mathrm{C}$ \\
ICI SWIR 640 P & Short-wave infrared & $640 \times 512$ pixel & $\pm 1{ }^{\circ} \mathrm{C}$ \\
Optris PI 450 & Thermal infrared & $382 \times 288$ pixels & $\pm 2{ }^{\circ} \mathrm{C}$ or $\pm 2 \%$ \\
ThermalCAM SC640 & Thermal infrared & $640 \times 480$ pixel & $\pm 2{ }^{\circ} \mathrm{C}$ or $\pm 2 \%$ \\
EasIR-9 & Thermal infrared & $288 \times 384$ pixel & $\pm 2{ }^{\circ} \mathrm{Cor} \pm 2 \%$ \\
thermoMAP & Thermal infrared & $640 \times 512$ pixel & $14 \mathrm{~cm} /$ pixel at $75 \mathrm{~m}$ \\
\hline
\end{tabular}

Some commonly used sensors are listed in the Table 1 for comparison. Compared with traditional remote sensing method, such as satellites, the thermal camera and UAVs make the data collection more flexible and lower cost. Thermal remote sensing images were first used in 1973 to estimate ET [39]. Temperature information is usually converted into land surface characteristics such as albedo, LAI, and surface emissivity. The TIR band is considered as the most important variable because it plays an important role in sensible heat flux and ground heat flux [40]. The cooled thermal cameras are usually more sensitive and accurate than uncooled thermal cameras [41]. But cooled thermal cameras are very big, expensive, and energy consuming [42]. So, they can hardly be used on UAV platform. In contrast, the uncooled thermal camera plays a more and more important role because they are light [43], low power consumption [44] and less expensive than cooled thermal cameras. As mentioned previously, uncooled thermal cameras have been widely used in UAV platform for ET estimation. Not only for ET, it also has been widely used in many other agricultural applications, such as plant disease detection [45], crop water stress estimation [46] [47] and soil moisture detection [48]. And most importantly, they can measure two of the most important parameters of ET estimation, soil temperature and tree canopy temperature, which are widely used in two source energy balance models, SEBAL, and METRIC.

The thermal camera has so many advantages, though, its micobolometer is not always sensitive and accurate [42]. Also, most thermal cameras are not always calibrated, which can only measure the relative temperature instead of the accurate value. In precision agriculture, however, most time it's necessary to measure the accurate temperature in many applications [43] such as crop monitoring [49], pest detection [50] and disease detection [45]. Unstable outdoor environmental factors can cause serious measurement drift during flight missions. Post-processing like mosaicking might further lead to measurement errors. We are using thermal camera more and more frequently with its limitations. To answer these two fundamental questions, in [51], the authors finished three experiments to research the best practice of thermal images collection for UAV. To calibrate TIR images, in [21], they used water body and rubber plates as cold and hot features. IR Flash Version 2 is usually used to process thermal UAV images for image format transformation.

\subsection{UAV path planning and image processing}

In this section, we discussed the potential of path planning and image processing methods for ET estimation. Recently, unmanned aerial vehicles have been widely used in agriculture, such as crop yield estimation [35], soil moisture monitoring, water stress estimation [33] and pest management [52]. Compared with traditional remote sensing tools, such as satellites, drones' flight time can be more flexible and more frequent in the field. And, drones can fly at lower altitude and can take higher spatial and possibly temporal resolution images and thermal images [51] of crops. As a low-cost scientific data collection platform, drones also make data acquisition relatively less expensive. While there are many advantages by using drones for agricultural applications [35], there is still a lot of work for drones when used for estimating evapotranspiration. Many researchers fly the drones in different height, 
using specialized equipment, controlling environments and relying on data analysis expertise [53]. Is there any optimal point where the data can be the best representation of crops? In [53], Brandon built a conceptual framework for describing the optimality as a function of spatial, spectral, and temporal factors which represent the best solution. As researchers try to understand the potential of the UAVs, efficient workflow, image processing methods, and better software are still under developing [54] [55] [56] [57].

\subsubsection{Pre-flight path planning}

Being used as a remote sensing platform, UAVs also create new research problems, such as drone image processing, and flight path planning. Flight missions were programmed by using Mission Planner software. The flight height was setup as $30 \mathrm{~m}, 60 \mathrm{~m}$, and $120 \mathrm{~m}$ in order to compare the image resolution's effect on pomegranate ET estimation. For all the flight missions, the overlap was set up as $75 \%$ to make sure the images can be stitched together during images pre-processing. The UAV sensors are designed to take images at nearly 0 nadir angle.

Researchers usually fly drones biweekly to collect data. If there is a drone crash, hardware issues, or unknown reasons, data may not be collected successfully. And, there is only one growing season each year. If data is missed, people have to wait for another year. In order to get enough data, for our research, we flew the drone Hover bi-weekly over the pomegranate field at noon during the growing season in 2017 and 2018. Table 2 is an example of data collection in 2018 by using Survey 2 (MAPIR, USA) and ICI 9460 P (ICI, USA) thermal camera.

Table 2. Multispectral and thermal images collection by UAV during the 2018 growing season at Parlier, CA, USA. -* means there is no data for that day.

\begin{tabular}{cccc}
\hline Date & Flight time & MAPIR Survey 2 & ICI 9460P \\
\hline $4-12-18$ & $12-2 \mathrm{pm}$ & $30,60,120 \mathrm{~m}$ & $30 \mathrm{~m}$ \\
$4-26-18$ & $12-2 \mathrm{pm}$ & $30,60,120 \mathrm{~m}$ & $30 \mathrm{~m}$ \\
$5-9-18$ & $12-2 \mathrm{pm}$ & $30,60,120 \mathrm{~m}$ & $30 \mathrm{~m}$ \\
$5-23-18$ & $12-2 \mathrm{pm}$ & $30,60,120 \mathrm{~m}$ & $30 \mathrm{~m}$ \\
$6-8-18$ & $12-2 \mathrm{pm}$ & $30,60,120 \mathrm{~m}$ & $-^{*}$ \\
$6-13-18$ & $12-2 \mathrm{pm}$ & $30,60,120 \mathrm{~m}$ & $30 \mathrm{~m}$ \\
$6-28-18$ & $12-2 \mathrm{pm}$ & $30,60,120 \mathrm{~m}$ & $-^{*}$ \\
$7-11-18$ & $12-2 \mathrm{pm}$ & $30,60,120 \mathrm{~m}$ & $-^{*}$ \\
$7-25-18$ & $12-2 \mathrm{pm}$ & $30,60,120 \mathrm{~m}$ & $30 \mathrm{~m}$ \\
$8-8-18$ & $12-2 \mathrm{pm}$ & $30,60,120 \mathrm{~m}$ & $30 \mathrm{~m}$ \\
$8-22-18$ & $12-2 \mathrm{pm}$ & $30,60,120 \mathrm{~m}$ & $30 \mathrm{~m}$ \\
$9-14-18$ & $12-2 \mathrm{pm}$ & $30,60,120 \mathrm{~m}$ & $30 \mathrm{~m}$ \\
$10-9-18$ & $12-2 \mathrm{pm}$ & $30,60,120 \mathrm{~m}$ & $30 \mathrm{~m}$ \\
$10-16-18$ & $12-2 \mathrm{pm}$ & $30,60,120 \mathrm{~m}$ & $30 \mathrm{~m}$ \\
$10-30-18$ & $12-2 \mathrm{pm}$ & $30,60,120 \mathrm{~m}$ & $30 \mathrm{~m}$ \\
\hline
\end{tabular}

\subsubsection{Image calibration}

In order to minimize the shading effect on the images, the drones are usually flying at noon with clear sky conditions. And, because each pixel in a drone image is a percentage of the reflected light, we need to calibrate the pixel value by using a known reflectance value. Therefore, the images of a color panel were taken right before and after the flight missions, servicing as the reflectance reference. 


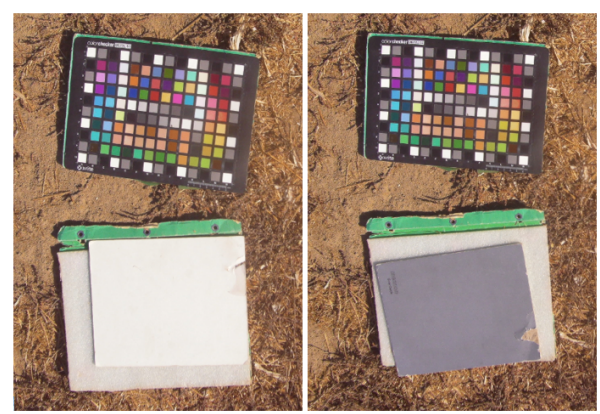

Figure 3. The images of a color panel were taken right before and after the flight missions, servicing as the reflectance reference.

It is important to take pictures of the reference panel immediately before and after the flight missions, because the solar angle and light intensity can change a lot based on an experiment in [47], which can cause inaccurate experiment results. Then, the digital number of the images were converted to reflectance by an empirical method in [58]

$$
\rho_{\lambda}=\frac{D N-D N_{d}}{D N_{w}-D N_{d}}
$$

where $\rho_{\lambda}$ is the reflectance and $D N$ is the digital number of the raw image. $D N_{d}$ and $D N_{w}$ are the dark relflectance point and white reflectance point in color checker respectively.

\subsubsection{Images stitching and orthomosaic image generation}

After the flight missions, all of the aerial images were stitched together to generate the orthomosaick images in PhotoScan (Agisoft LLC, Russian). As shown in Table 3, there are usually three steps for image processing, which includes aligning photos, building mesh (optional) and generating orthomosaick. For example, the Agisoft Photoscan settings and workflow for RGB and NIR images (by MAPIR Survey 2) are listed in Table 3.

Table 3. Orthomosaic images generation workflow in Agisoft Photoscan

\begin{tabular}{ccc}
\hline Step 1 : Align Photos & Step 2 : Build Mesh & Step 3 : Build Orthomosaick \\
\hline Accuracy: Medium & Surface type: Height field (2.5D) & Type: Planar \\
Generic preselection: Yes & Source data: Sparse cloud & Projection plane: TOP XY \\
Key point limit: 40,000 & Face count: Medium (30,000) & Rotation angle: 0 \\
Tie point limit: 4,000 & Interpolation: Enabled (default) & Surface: Mesh \\
Adaptive camera model fitting: No & Point classes: All & Blending mode: Mosaic (default) \\
& Caculate vertex colors: Yes & Enable hole filling: Yes \\
& & Enable back-face culling: No \\
\hline
\end{tabular}



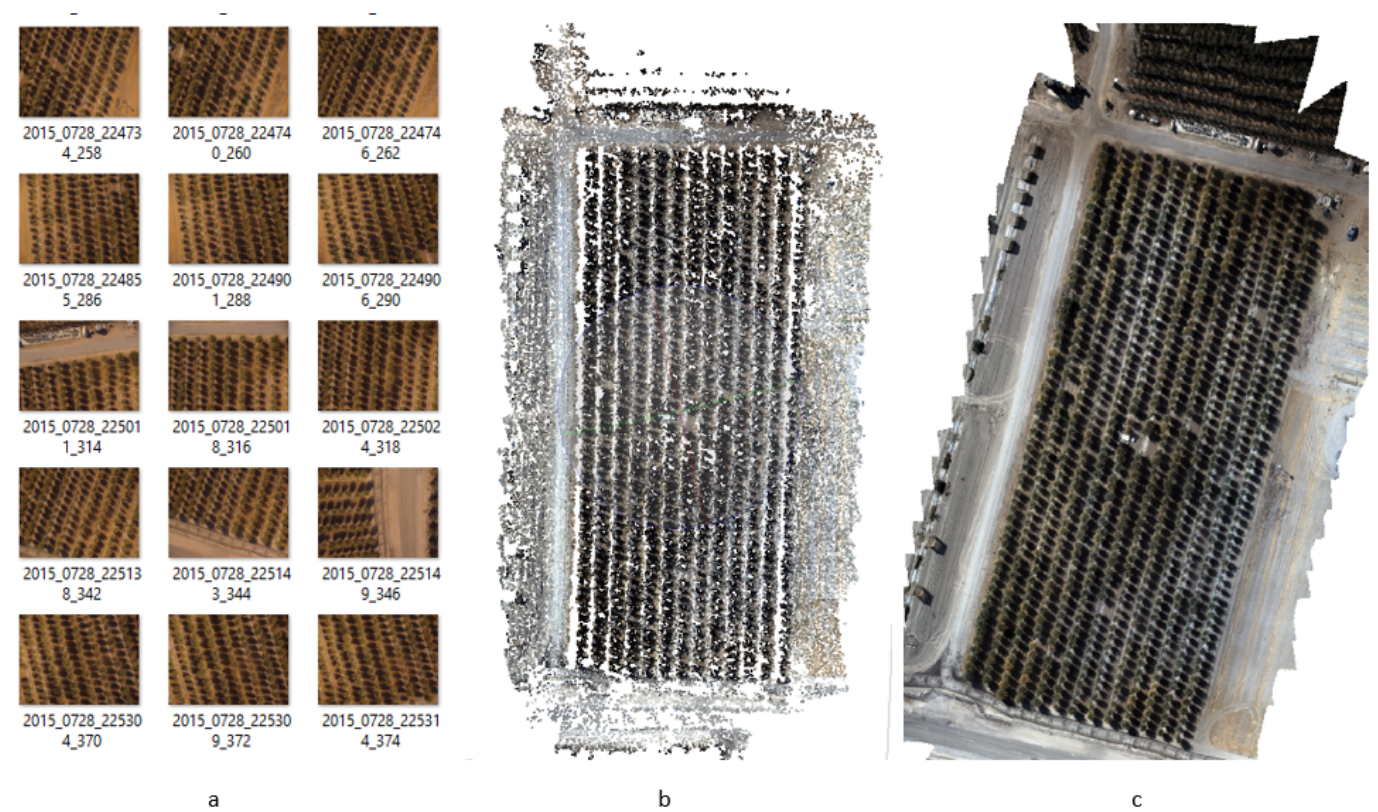

Figure 4. This is a image processing workflow to generate orthomosaick image for a pomegranate field (a) Some drone image examples taken by MAPIR . (b) Tie points images generated by Photoscan. (c) The orthomosaick image for the pomegranate field.

\subsubsection{Post-processing calibrated images}

In this subsection, a MATLAB code was written in order to calculate the normalized difference vegetation index (NDVI) by using the orthomosaick image. Many studies have used NDVI from remote sensing platform to help estimate crop coefficient values on crops, such as [59] [60] [61]. Then, crop coefficient can be applied to creating local and regional crop evapotranspiration $\left(\mathrm{ET}_{c}\right)$ maps. In [62] [63], they used a direct method to estimate ET by using the correlation between the ET, the remote sensing data, and the meteorological data. It is based on the assumption that daily ET has a correlation with the surface and air temperature. According to the relationship between NDVI and surface temperature, [64] [65] proposed a new direct method, which shows that NDVI and surface temperature have effect on the ET quantity. The relationship between the NDVI and surface temperature is strong, though, it changes by seasons [65]. LAI and fractional vegetation cover are also often calculated by using NDVI according to an empirical LAI-NDVI relation [66] [67].

Therefore, it is important to get NDVI values first before proceeding to further ET research. To calculate the NDVI, the following equation is used:

$$
N D V I=\frac{\rho_{N I R}-\rho_{R}}{\rho_{N I R}+\rho_{R}}
$$

where $\rho_{N I R}$ and $\rho_{R}$ are the reflectance of near-infrared and red wavebands, respectively. After generating the NDVI image, QGIS was used to generate the pseudocolor map for the NDVI map, as shown in Figure 5. 


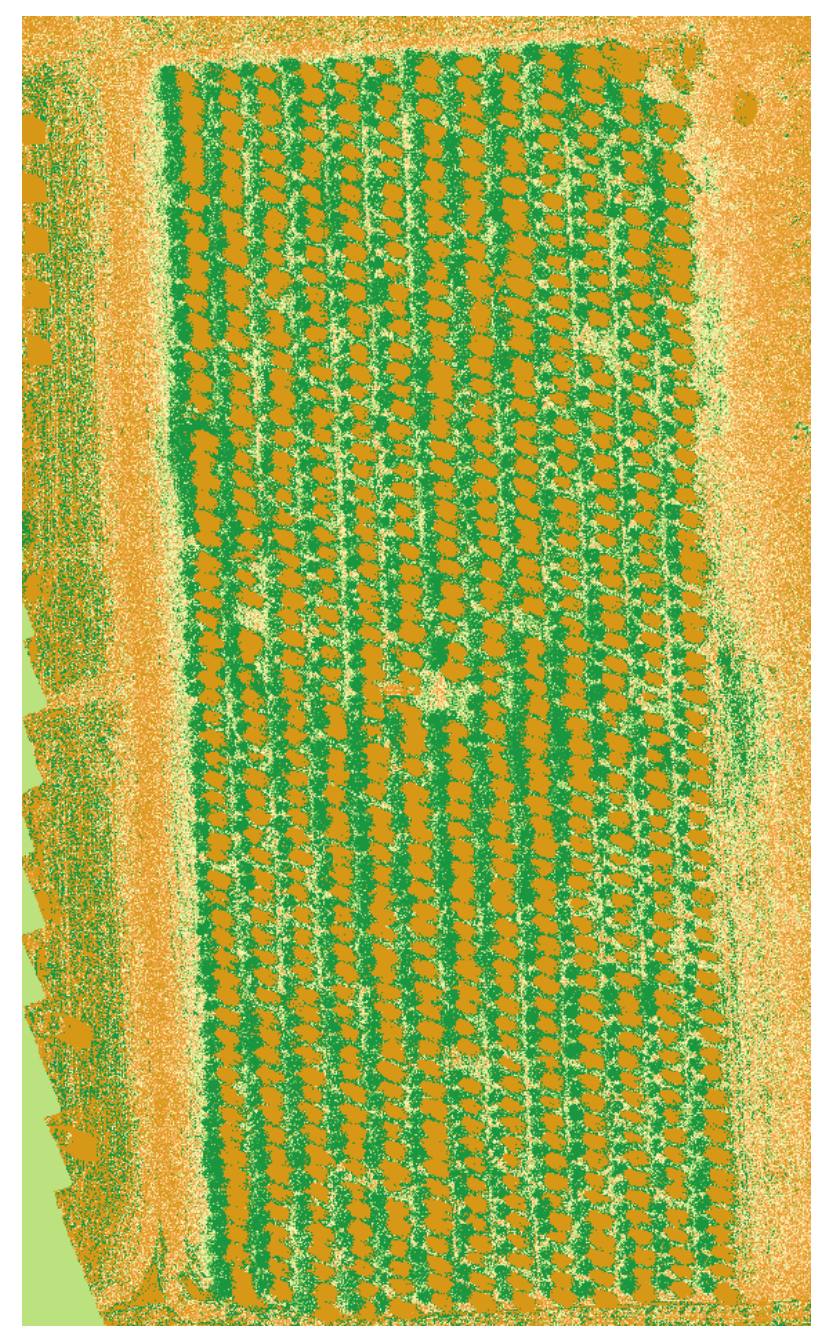

Figure 5. NDVI map for a pomegranate field at USDA

\section{ET Estimation Methods for UAV}

Most ET estimation methods for UAVs are based on satellites remote sensing methods, the most widely used is energy balance models. TSEB, TSEB-PT, and DTD are introduced in this section. METRIC is also mentioned because of its potential in UAVs application. Researchers need to preprocess the images to input them in the METRIC model, because this model is originally for satellites images. But some research still shows good results [68].

\subsection{Two source energy balance (TSEB) models}

The TSEB is proposed by Norman [26] and modified by Norman and Kustas to improve the accuracy of LE estimation [24] [69] [70]. Based on [71] [72], the TSEB is effective over homogeneous land and environmental conditions. And, it can reproduce fluxes with similar results to tower-based observations. The TSEB model separates the land surface temperature into soil surface temperature and vegetation surface temperature, and it considers sensible and latent heat fluxes are transferred to the atmosphere from both surface temperature components, as shown in the following equations [37].

$$
\begin{gathered}
R_{n}=R_{n s}+R_{n c}=H+L E+G, \\
R_{n s}=H_{s}+L E_{s}+G, \\
R_{n c}=H_{c}+L E_{c},
\end{gathered}
$$


where $R_{n}$ is the net radiation $\left(\mathrm{W} \mathrm{m}^{-2}\right)$. The soil net radiation $\left(\mathrm{W} \mathrm{m}^{-2}\right)$ is represented by $R_{n s}$ and $R_{n c}$ is the canopy net radiation $\left(\mathrm{W} \mathrm{m}^{-2}\right) . H$ is the sensible heat flux $\left(\mathrm{W} \mathrm{m}^{-2}\right) . H_{s}$ and $H_{c}$ are soil sensible heat flux $\left(\mathrm{W} \mathrm{m}^{-2}\right)$ and canopy sensible heat flux $\left(\mathrm{W} \mathrm{m}^{-2}\right)$ respectively. $L E$ is the latent heat flux (W $\left.\mathrm{m}^{-2}\right) . L E_{s}$ and $L E_{c}$ are soil latent heat flux $\left(\mathrm{W} \mathrm{m}^{-2}\right)$ and canopy latent heat flux $\left(\mathrm{W} \mathrm{m}^{-2}\right)$ respectively. $G$ is the soil heat flux $\left(\mathrm{W} \mathrm{m}^{-2}\right)$.

$$
\begin{aligned}
& H_{s}=\rho C_{p} \frac{T_{s}-T_{a c}}{R_{s}}, \\
& H_{c}=\rho C_{p} \frac{T_{c}-T_{a c}}{R_{x}},
\end{aligned}
$$

where $\rho$ is the air density $\left(\mathrm{kg} \mathrm{m}^{-3}\right), C_{p}$ is the specific heat of air $\left(\mathrm{J} \mathrm{kg}^{-1} \mathrm{~K}^{-1}\right) . T_{a c}$ is the air temperature in the vegetation. $R_{s}$ is the resistance to heat flux above the soil surface $\left(\mathrm{s} \mathrm{m}^{-1}\right) . R_{x}$ is the boundary

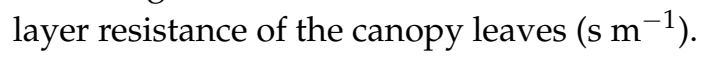

The net radiation is divided into two parts, the soil net radiation and the canopy net radiation [73] [74].

$$
\begin{gathered}
R_{n s}=\tau_{l} L_{d}+\left(1-\tau_{l}\right) \varepsilon_{c} \sigma T_{c}^{4}-\varepsilon_{s} \sigma T_{s}^{4}+\tau_{s}\left(1-\alpha_{s}\right) S_{d}, \\
R_{n c}=\left(1-\tau_{l}\right)\left(L_{d}+\varepsilon_{s} \sigma T_{s}^{4}-2 \varepsilon_{c} \sigma T_{c}^{4}\right)+\left(1-\tau_{s}\right)\left(1-\alpha_{c}\right) S_{d},
\end{gathered}
$$

where $\tau_{l}$ and $\tau_{s}$ are the longwave and shortwave radiation transmittances through the canopy. $L_{d}$ and $S_{d}$ are the incoming longwave and shortwave radiation $\left(\mathrm{W} \mathrm{m}^{-2}\right)$, which are usually measured from a nearby weather station. $\sigma$ is the Stefan-Boltzmann constant, which is approximately $5.67 \times 10^{-8}(\mathrm{~W}$ $\left.\mathrm{m}^{-2} \mathrm{~K}^{-4}\right)$. $\varepsilon$ is the surface emissivity. $\alpha$ is the surface albedo. And $T$ is the surface temperature $(\mathrm{K})$. Subscripts "s" and "c" mean soil and canopy.

In the TSEB model, the land surface temperature $T_{R}(\theta)$ is related to the soil and canopy component temperatures. The fraction of vegetation cover viewing angle $\theta$ also has effect on the estimation of $T_{R}(\theta)$, as shown in the following equation

$$
T_{R} \approx\left[f_{c}(\theta) T_{c}^{4}+\left(1-f_{c}(\theta)\right) T_{s}^{4}\right]^{\frac{1}{4}},
$$

where $f_{c}(\theta)$ is the fractional vegetation cover observed as angle $\theta$ by radiometer. To calculate $f_{\mathcal{c}}(\theta)$, the following equation [75] was used

$$
f_{\mathcal{C}}(\theta)=1-e^{\frac{-0.5 \Omega(\theta) L A I}{\cos (\theta)}} .
$$

The UAV can help get maps of NDVI, LAI, $f_{\mathcal{c}}(\theta)$, and $T_{R}(\theta)$, which are the most important input data for TSEB model. $L E_{c}$ is initially estimated by using Priestley-Taylor formulation:

$$
L E_{c}=\alpha_{P T} f_{G} \frac{\Delta}{\Delta+\gamma} R_{n c}
$$

where $\alpha_{P T}$ is the Priestley-Taylor coefficient. $f_{G}$ is the LAI fraction. $\Delta$ is the slope of the saturation vapor pressure-temperature curve $\left(\mathrm{Pa} \mathrm{K}^{-1}\right) \cdot \gamma$ is the psychrometric constant $\left(\mathrm{Pa} \mathrm{K}^{-1}\right)$.

\subsection{TSEB-PT model}

In [27], the authors used two source energy balance models, the Priestley-Taylor TSEB (TSEB-PT) and the Dual-Temperature-Difference (DTD) when flying a fixed-wing UAV. The TSEB was first proposed by [76]. In 1995, Norman [26] applied an iterative process in order to derive the canopy and soil temperature. The method is based on the assumption of canopy transpiration, which was shown in Priestley and Taylor potential evapotranspiration [77]. Therefore, this method is called TSEB-PT in order to differentiate it from other TSEB methods. The TSEB-PT method splits the surface temperature into two layers, the canopy $T_{\mathcal{C}}$ and soil $T_{S}$ temperatures. The calculation of sensible heat flux and latent 
heat flux for canopy and soil are separate, which makes the parameterization of resistances easier compared with a single layer model.

\subsection{Dual-Temperature-Difference DTD model}

The DTD model was proposed in [78], which separates the land surface temperature into vegetation and soil temperatures. Then, it calculates the surface energy balance components with the same procedures as TSEB-PT. And, the DTD model can add one more input dataset, the land surface temperature retrieved one hour after sunrise. Because the energy fluxes are minimal at sunrise, it can help minimize the bias in the temperature estimation. In [79], Guzinski produced surface energy flux successfully by using the DTD model. The author used night observations to substitute for the early morning observation. However, the temporal resolution of the satellite observations is still limited, especially when the weather conditions are bad, such as overcast as satellite thermal infrared observations cannot penetrate clouds. The incapacity to collect data in overcast situations applies to all satellite sensors except for those operating in the microwaves region [79].

The calculation of soil heat flux $G$ is also different because the radiometric temperature is dissimilar between midday and sunrise observations. This difference can be used to estimate the soil surface temperature variations. Soil heat flux is calculated based on the model of [80]. For more details about the TSEB-PT and DTD equations, see [81] [82].

By using the UAV platform, it can get better data in accordance with the DTD requirements and during overcast conditions [83].

\subsection{METRIC model}

METRIC is originally a satellite images processing model for estimating ET as a residual of the energy balance, which was developed by University of Idaho. METRIC has a self-calibration process which contains ground-based hourly reference ET and the selection of hot, cold pixels [84]. The METRIC is based on SEBAL. SEBAL's innovative component is that the model uses a near-surface temperature gradient, $d T$. It helps eliminating the need for absolute surface temperature calibration [11]. SEBAL uses Ts, $\rho$, NDVI and their relationships to calculate the surface fluxes [18]. And SEBAL has been evaluated all over the world [85] [86] [87] [88] [89]. In METRIC, they use the SEBAL to estimate $d T$. Therefore, there is no need to get accurate aerodynamic surface temperature. In [1], the author summarized three differences between the SEBAL and METRIC. First, for the cold pixel, the METRIC does not consider sensible heat flux as zero. Instead, a surface soil water balance is applied to set ET as zero and 1.05 times reference ET at hot and cold pixels respectively. Reference ET is calculated by using the standardized ASCE Penman-Monteith equation. Second, in METRIC, cold pixels are selected in agricultural settings instead of biophysical characteristics. Third, the extrapolation of instantaneous ET is based on reference ET instead of the actual evaporative fraction.

Allan [17] compared the ET estimation between the METRIC and lysimeter near the Montpelier, Idaho. The difference between METRIC and lysimter is only $4 \%$. $L E$ is the rate of latent heat loss from the surface because of the ET. METRIC estimates ET as a residual of the energy balance

$$
L E=R_{n}-G-H,
$$

where $R_{n}$ is the net radiation ( $\mathrm{W} \mathrm{m}^{-2}$ ), which is calculated by solving the radiation balance as described in [90]. $H$ is for sensible heat flux $\left(\mathrm{W} \mathrm{m}^{-2}\right)$, which is a function of air density, air specific heat, temperature difference between two canopy heights, the aerodynamic resistance, and temperature gradient. $L E$ is for latent heat flux $\left(\mathrm{W} \mathrm{m}^{-2}\right)$ and $\mathrm{G}$ is for soil heat flux $\left(\mathrm{W} \mathrm{m}^{-2}\right)$.

For the $R_{n}$, it can be calculated based on the following equation [25]:

$$
R_{n}=(1-\alpha) R_{s \downarrow}+R_{L \downarrow}-R_{L \uparrow}-\left(1-\varepsilon_{o}\right) R_{L \downarrow}
$$


where $R_{s \downarrow}$ is the incoming short-wave radiation $\left(\mathrm{W} \mathrm{m}^{-2}\right) . \quad \alpha$ is the surface albedo, which is dimensionless. $R_{L \downarrow}$ and $R_{L \uparrow}$ are the incoming long-wave radiation $\left(\mathrm{W} \mathrm{m}^{-2}\right)$ and outgoing long-wave radiation $\left(\mathrm{W} \mathrm{m}^{-2}\right)$, respectively. $\varepsilon_{0}$ is the thermal emissivity, which is also dimensionless.

$R_{s \downarrow}$ is usually calculated by the following equation if the sky is clear

$$
R_{s \downarrow}=\frac{G_{s c} \cos \theta_{r e f} \tau_{s w}}{d^{2}}
$$

where $G_{s c}$ is the solar constant $\left(1367 \mathrm{~W} \mathrm{~m}^{-2}\right) . \theta_{\text {ref }}$ is the solar incidence angle. $d$ is the relative distance between the Earth and the Sun. $\tau_{s w}$ is the broad band atmospheric transmissivity, which is calculated by using the following equation [91]

$$
\tau_{s w}=0.35+0.627 \exp \left[\frac{-0.00146 P}{K_{t} \cos \theta_{\text {hor }}}-0.075\left(\frac{W}{\cos \theta_{\text {hor }}}\right)^{0.4}\right],
$$

where $P$ is the atmospheric pressure (kPa). $W$ is the water in the atmosphere $(\mathrm{mm}) . \theta_{\text {hor }}$ is the solar zenith angle over a horizontal surface. $K_{t}$ is the unitless turbidity coefficient. $P$ and $W$ are also calculated based on [91]

$$
\begin{gathered}
P=101.3\left(\frac{293-0.0065 z}{293}\right)^{5.26}, \\
W=0.14 e_{a} P_{\text {air }}+2.1,
\end{gathered}
$$

where $z$ is the elevation above the sea level. $e_{a}$ is the near-surface vapor pressure $(\mathrm{kPa})$.

For the incoming and outgoing long wave radiation $R_{L \downarrow}$ and $R_{L \uparrow}$, they are calculated by using Stefan-Boltzmann equation

$$
\begin{aligned}
& R_{L \uparrow}=\varepsilon_{o} \sigma T_{s}^{4}, \\
& R_{L \downarrow}=\varepsilon_{a} \sigma T_{a}^{4},
\end{aligned}
$$

where $\varepsilon_{a}$ is effective atmospheric emissivity, which is usually calculated by an empirical equation

$$
\varepsilon_{a}=0.85\left(-\ln \tau_{s w}\right)^{0.09},
$$

$H$ is computed from surface roughness, wind speed, surface temperature ranges. The sensible heat flux is considered as the most difficult term to calculate in the energy balance equation, in order to calculate the $H$, an aerodynamic function is used:

$$
H=\rho_{a i r} C_{p} \frac{d T}{r_{a h}},
$$

where $r_{a h}$ is the aerodynamic resistance $\left(\mathrm{s} \mathrm{m}^{-1}\right)$ between two surface height. In METRIC, $r_{a h}$ is usually calculated by using the wind speed and an iterative stability correction, as shown in the following equation

$$
r_{a h}=\frac{\ln \left(z_{2} / z_{1}\right)}{u_{*} k}
$$

where $z_{1}$ and $z_{2}$ are heights above the zero-plane displacement of the vegetation. $k$ is the von Karman constant $(0.41) \cdot u_{*}$ is the friction velocity $\left(\mathrm{m} \mathrm{s}^{-1}\right)$, which is calculated by using

$$
u_{*}=\frac{k u_{200}}{\ln \left(200 / z_{o m}\right)}
$$

where $u_{200}$ is the wind speed at a blending height $200 \mathrm{~m}$. And $z_{o m}$ is the momentum roughness length (m). 
$d T$ is the temperature difference between the air and the surface. A strong linear relation between the $d T$ and the surface temperature were found in [25] [18] [92] [93]. The equation for the $d T$ and the surface temperature is shown as

$$
d T=a+b T_{s}
$$

where $a$ and $b$ are derived parameters empirically based on two extreme hot and cold pixels. These hot and cold pixels defined the boundary of the sensible heat flux. The cold pixel represents a well-watered area with no water stress. The $H$ is assumed to be minimum and ET should be maximum. The hot pixel represents a dry and bare field where $H$ is maximum and ET is almost zero. Hot and cold pixels must be selected by experienced users, which makes it difficult for beginner level researchers.

In METRIC, $G$ is the heat storage in soil and vegetation, which can be estimated by $R_{n}$ surface temperature and vegetation index [85] according to

$$
\frac{G}{R_{n}}=\left(T_{s}-273.15\right)(0.0038+0.0074 \alpha)\left(1-0.98 N D V I^{4}\right) .
$$

Another equation used for estimating $G$ is proposed by Tasumi [94], who used the data collected by [95].

$$
\begin{gathered}
\frac{G}{R_{n}}=0.05+0.18 e^{-0.521 L A I}(L A I \geq 0.5), \\
\frac{G}{R_{n}}=1.80 \frac{\left(T_{s}-273.15\right)}{R_{n}}+0.084(L A I \leq 0.5) .
\end{gathered}
$$

Based on Tasumi's experiment results [94], the two above calculation methods can measure $G$ accurately for irrigated plants in Kimberly, Idaho.

\section{Results and Discussion}

The comparison between UAV methods and results from other traditional remote sensing studies reveals that the data from the UAV platform and the light weight cameras can estimate the surface energy fluxes with similar accuracy estimated by using satellite data. Therefore, the UAV data can be used for modelling ET estimation with high confidence.

\subsection{TSEB models}

Mounted on the UAV, multispectral sensors and thermal camera can help obtain high-resolution images. In [37], the authors used a two-source energy balance model for a sub-field and plant canopy scale ET monitoring. It is concluded that the TSEB model can simulate the energy balance components in two vineyards with mean absolute error (MAE) ranging from 15 to $90 \mathrm{~W} \mathrm{~m}^{-2}$. They found that the TSEB model is fairly robust and able to calculate LE and ET values under a varying environmental conditions. By using the TSEB, the $T_{S}$ and $T_{\mathcal{C}}$ have a bias of $0.5{ }^{\circ} \mathrm{C}$ and RMSD on the order of $2.5^{\circ} \mathrm{C}$. The accuracy is similar with the following papers [96] [70] [69] [97] , in which the RMSD values are between 2.4 to $5.0{ }^{\circ} \mathrm{C}$ for $T_{s}$ and 0.83 to $6.4{ }^{\circ} \mathrm{C}$ for $T_{c}$.

For a lightweight thermal camera mounted on a UAV, Hoffmann [27] concatenated the LST thermal images into orthomosaick, then applied as the input for TSEB model. Based on the comparison between UAV fluxes and eddy covariance (EC) fluxes, the $R_{n}$ for TSEB is in good agreement with $R_{n}$ measured from EC with a RMSE of $44 \mathrm{~W} \mathrm{~m}^{-2}$. The sensible heat flux $(H)$ for DTD has RMSE and MAE values of $59 \mathrm{~W} \mathrm{~m}^{-2}$ and $49 \mathrm{~W} \mathrm{~m}^{-2}$. The soil heat flux $(G)$ are underestimated, which has RMSE and MAE values of $48 \mathrm{~W} \mathrm{~m}^{-2}$ and $45 \mathrm{~W} \mathrm{~m}^{-2}$. For the latent heat flux, DTD has RMSE and MAE values of $67 \mathrm{~W} \mathrm{~m}^{-2}$ and $57 \mathrm{~W} \mathrm{~m}^{-2}$. They concluded that the TIR camera placed on a UAV platform can provide high spatial and temporal resolution data for estimating energy balance fluxes of ET. This study show similar results with Guzinski's work [81], who applied the TSEB-PT at the same site but used satellites 
images instead of UAV images. In [81], the RMSE is $46 \mathrm{~W} \mathrm{~m}^{-2}$ for $R_{n}, 56 \mathrm{~W} \mathrm{~m}^{-2}$ for $H$, and $66 \mathrm{~W} \mathrm{~m}^{-2}$ for LE.

In [36], the RSEB algorithm was well implemented and only the climatic parameters, such as $T_{a}$, wind speed are measured as the input data. UAV images are used for calculating the NDVI and $T_{s}$. The authors evaluate the RSEB algorithm by $H$ and $L E$. Results show that the algorithm estimates $L E$ and $H$ with errors of $7 \%$ and $5 \%$. The RMSE and MAE for $L E$ are 50 and $43 \mathrm{~W} \mathrm{~m}^{-2}$. And, the RMSE and MAE for $H$ are 56 and $46 \mathrm{~W} \mathrm{~m}^{-2}$. It also concludes that high spatial resolution maps are capable to detect significant differences between the energy balance fluxes above the tree canopy and the soil surface between rows. UAV could also be used to help the satellite platforms for estimating spatial variability of ET maps.

\subsection{SEBAL and METRIC models}

In [68], Montibeller used multispectral and thermal camera to collect data for running the SEBAL model. To evaluate the estimated energy fluxes, they used linear regression models, residual plots, RMSE, and MAE methods. The $\mathrm{R}^{2}$ for the $\mathrm{R}_{n}$ is 0.71 , which was underestimated about $17 \%$ compared with the flux towers. The RMSE for the $\mathrm{R}_{n}$ is $6.09 \mathrm{~W} \mathrm{~m}^{-2}$. For the $\mathrm{G}$, the $\mathrm{R}^{2}$ is 0.17 , with a RMSE of $11.23 \mathrm{~W} \mathrm{~m}^{-2}$. The $\mathrm{R}^{2}$ for the $\mathrm{H}$ is 0.5 , with a RMSE of $8.84 \mathrm{~W} \mathrm{~m}^{-2}$. It overestimate the flux by $5 \%$. For the LE , $\mathrm{R}^{2}$ is $0.82 \mathrm{~m}$, with a RMSE of $2.67 \mathrm{~W} \mathrm{~m}^{-2}$. The research also shows that the ET rate is relevant to the crop growth stage. Corn, for example, has higher ET rates up until the tassel appears. However, the relationship between the NDVI and ET is very poor, further study need to be explored. Overall, the research proves that SEBAL model can be used for estimating ET with UAV very well. The algorithms being used by [68] were automated by Python, which facilitates the data processing foe ET estimation. This method can also be used for decision making in real time, which can monitor the waster consumption of each crop in the field.

\section{Conclusions}

According to the previous review, it shows that each ET estimation model has its own advantages and disadvantages. For example, METRIC/SEBAL methods, they are more recognized by the remote sensing researchers, but they are based on satellite (Landsat) platforms. It may require more efforts to make it work with UAV images. The TSEB model is less widely known, but it seems that it offers more potential for UAV applications in many crop conditions, for example, tree crops like pomegranate, nectarine, and almonds. When flying a drone, weather condition, field scale, flight time and many other factors should also be considered in order to choose the appropriate algorithms for ET estimation.

ET estimation methods and related agricultural applications have significantly been developing over the past decades. Although remote sensing ET models can help get relatively accurate spatial distribution ET data, important outstanding ET estimation questions are still from local to large scales because of the deficiency of our observation capability. No existing methods can fully satisfy the spatial, temporal, spectral, and accuracy requirements for ET-based science and applications [98]. Therefore, innovative methods or models for ET estimation are required by using UAVs. In [98], the author proposed five requirements to map ET with high fidelity in the future, which are high frequency, high spatial resolution, high temporal resolution, large spatial coverage, and long-term monitoring. High frequency will improve the differentiation of water stress between crops, which enables more efficient water management. High spatial resolution can help detect spatially heterogeneous responses to the water stress. Because ET is highly variable within and among days, high temporal resolution can help detect crops ET in real-time. Large spatial coverage can help detect large scale drought. And long term monitoring will be important to record ET variability. 

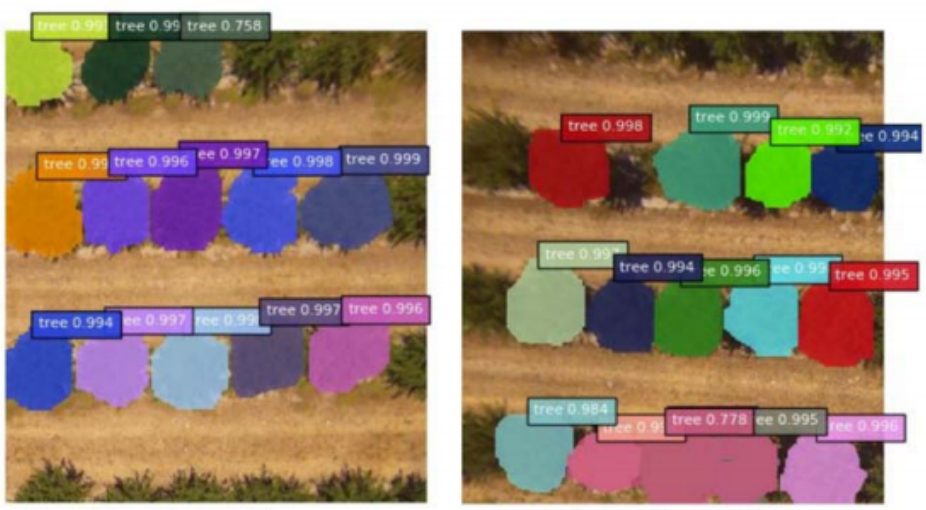

Figure 6. ET estimation in a single tree level

Compared with other satellites based remote sensing methods, UAV platform and light weight sensors can provide better quality, higher spatial and temporal resolution images. UAV can be used to estimate ET in excellent scale and with flexible flight schedules. In the future, tree-by-tree ET estimation would be useful to analyze the crops temporal and spatial variability in the field, as shown in Figure 6. In the [34], they used a deep learning neural network to train UAV images to identify tree canopies at very high accuracy, which have a great chance to be used in the future to estimate ET of a single tree. Also, further research should be focused on remote sensing algorithms and their applications on different crops.

Author Contributions: Haoyu Niu designed the experiments, processed and analyzed the UAV images, and wrote the original manuscript draft. Tiebiao Zhao, Dong Wang, and YangQuan Chen contributed to the results interpretation and discussions and editing of the manuscript.

Funding: This research is supported in part by USDA NIFA grant 2016-38422-25551 (2016-2020) entitled "Innovation and Entrepreneurship Programs to Train Hispanic Students for Future Agricultural and Food Industry".

Acknowledgments: Thanks go to Dong Sen Yan, Joshua Ahmed, Allan Murillo, Stella Zambrzuski and Christopher Currier for flying drones or collecting field measurements. We gratefully acknowledge the support of NVIDIA Corporation with the donation of the Titan X Pascal GPU used for this research.

Conflicts of Interest: The authors declare no conflict of interest.

\section{Abbreviations}

The following abbreviations are used in this manuscript:

MDPI Multidisciplinary Digital Publishing Institute

ET Evapotranspiration

UAV Unmanned Aerial Vehicles

METRIC Mapping Evapotranspiration at high Resolution with Internalized Calibration

NDVI Normalized Difference Vegetation Index

SEBAL Surface Energy Balance Algorithm for Land

RGB Red Green and Blue

RSEB Remote sensing energy balance

TSEB Two source energy balance

TIR Thermal infrared

FOV Field of View

NIR Near infrared

JPEG Joint Photographic Experts Group

SWIR Short-wave infrared

MAE Mean absolute error 


\section{Appendix A MATLAB code and Photoscan settings}

Appendix A.1 Matlab code for calculating drone image NDVI

The Matlab code is attached here for calculating NDVI of drone images, which can be found at Github: https://github.com/niuhaoyu16/NDVI-for-drone-images

Appendix A.2 Agisoft Photoscan image processing settings

Agisoft Photoscan image processing settings is available at Github: https://github.com/ niuhaoyu16/AgisoftPhotoscan-Images-processing-settings

\section{Appendix B Open source python code for METRIC and TSEB}

Appendix B.1 Python code for TSEB

PyTSEB is available at Github: https:/ / github.com/hectornieto/pyTSEB

Appendix B.2 Python code for METRIC

PyMETRIC is available at Github: https://github.com/hectornieto/pyMETRIC

\section{References}

1. Liou, Y.A.; Kar, S. Evapotranspiration estimation with remote sensing and various surface energy balance algorithms-A review. Energies 2014, 7, 2821-2849.

2. Verstraeten, W.; Veroustraete, F.; Feyen, J. Assessment of evapotranspiration and soil moisture content across different scales of observation. Sensors 2008, 8, 70-117.

3. Eden, U. Drought assessment by evapotranspiration mapping in Twente, the Netherlands; University of Twente Faculty of Geo-Information and Earth Observation (ITC), 2012.

4. Kaplan, S.; Myint, S.W.; Fan, C.; Brazel, A.J. Quantifying outdoor water consumption of urban land use/land cover: sensitivity to drought. Environmental management 2014, 53, 855-864.

5. Wetzel, P.J.; Chang, J.T. Evapotranspiration from nonuniform surfaces: A first approach for short-term numerical weather prediction. Monthly Weather Review 1988, 116, 600-621.

6. Allen, R.G.; Pereira, L.S.; Raes, D.; Smith, M. FAO Irrigation and drainage paper No. 56. Rome: Food and Agriculture Organization of the United Nations 1998, 56, e156.

7. Liu, C.; Zhang, X.; Zhang, Y. Determination of daily evaporation and evapotranspiration of winter wheat and maize by large-scale weighing lysimeter and micro-lysimeter. Agricultural and Forest Meteorology 2002, $111,109-120$.

8. Xu, C.Y.; Singh, V. Evaluation of three complementary relationship evapotranspiration models by water balance approach to estimate actual regional evapotranspiration in different climatic regions. Journal of Hydrology 2005, 308, 105-121.

9. Idso, S.B.; Jackson, R.D.; Reginato, R.J. Estimating evaporation: a technique adaptable to remote sensing. Science 1975, 189, 991-992.

10. Grismer, M.E.; Orang, M.; Snyder, R.; Matyac, R. Pan evaporation to reference evapotranspiration conversion methods. Journal of irrigation and drainage engineering 2002, 128, 180-184.

11. Allen, R.; Irmak, A.; Trezza, R.; Hendrickx, J.M.; Bastiaanssen, W.; Kjaersgaard, J. Satellite-based ET estimation in agriculture using SEBAL and METRIC. Hydrological Processes 2011, 25, 4011-4027.

12. Angus, D.; Watts, P. Evapotranspiration-How good is the Bowen ratio method? In Developments in Agricultural and Managed Forest Ecology; Elsevier, 1984; Vol. 13, pp. 133-150.

13. Fritschen, L.J. Accuracy of evapotranspiration determinations by the Bowen ratio method. Hydrological Sciences Journal 1965, 10, 38-48.

14. Nagler, P.L.; Scott, R.L.; Westenburg, C.; Cleverly, J.R.; Glenn, E.P.; Huete, A.R. Evapotranspiration on western US rivers estimated using the Enhanced Vegetation Index from MODIS and data from eddy covariance and Bowen ratio flux towers. Remote sensing of environment 2005, 97, 337-351. 
15. Su, Z. The Surface Energy Balance System (SEBS) for estimation of turbulent heat fluxes. Hydrology and earth system sciences 2002, 6, 85-100.

16. Kustas, W.; Anderson, M. Advances in thermal infrared remote sensing for land surface modeling. Agricultural and Forest Meteorology 2009, 149, 2071-2081.

17. Allen, R.G.; Tasumi, M.; Morse, A.; Trezza, R. A Landsat-based energy balance and evapotranspiration model in Western US water rights regulation and planning. Irrigation and Drainage systems 2005, 19, 251-268.

18. Bastiaanssen, W.G.; Pelgrum, H.; Wang, J.; Ma, Y.; Moreno, J.; Roerink, G.; Van der Wal, T. A remote sensing surface energy balance algorithm for land (SEBAL).: Part 2: Validation. Journal of hydrology 1998, 212, 213-229.

19. Bastiaanssen, W.G.; Menenti, M.; Feddes, R.; Holtslag, A. A remote sensing surface energy balance algorithm for land (SEBAL). 1. Formulation. Journal of hydrology 1998, 212, 198-212.

20. Kustas, W.P.; Norman, J.M. A two-source approach for estimating turbulent fluxes using multiple angle thermal infrared observations. Water Resources Research 1997, 33, 1495-1508.

21. Park, S. Estimating plant water stress and evapotranspiration using very-high-resolution (VHR) UAV imagery. PhD thesis, 2018.

22. Quattrochi, D.A.; Luvall, J.C. Thermal infrared remote sensing for analysis of landscape ecological processes: methods and applications. Landscape ecology 1999, 14, 577-598.

23. Moran, M.S.; Jackson, R.D. Assessing the spatial distribution of evapotranspiration using remotely sensed inputs. Journal of Environmental Quality 1991, 20, 725-737.

24. Kustas, W.; Norman, J. Use of remote sensing for evapotranspiration monitoring over land surfaces. Hydrological Sciences Journal 1996, 41, 495-516.

25. Allen, R.G.; Tasumi, M.; Trezza, R. Satellite-based energy balance for mapping evapotranspiration with internalized calibration (METRIC) -Model. Journal of irrigation and drainage engineering 2007, 133, 380-394.

26. Norman, J.M.; Kustas, W.P.; Humes, K.S. Source approach for estimating soil and vegetation energy fluxes in observations of directional radiometric surface temperature. Agricultural and Forest Meteorology 1995, 77, 263-293.

27. Hoffmann, H.; Nieto, H.; Jensen, R.; Guzinski, R.; Zarco-Tejada, P.; Friborg, T. Estimating evaporation with thermal UAV data and two-source energy balance models. Hydrology and Earth System Sciences 2016, 20, 697-713.

28. Cammalleri, C.; Anderson, M.; Gao, F.; Hain, C.; Kustas, W. A data fusion approach for mapping daily evapotranspiration at field scale. Water Resources Research 2013, 49, 4672-4686.

29. Díaz-Varela, R.; de la Rosa, R.; León, L.; Zarco-Tejada, P. High-resolution airborne UAV imagery to assess olive tree crown parameters using $3 \mathrm{D}$ photo reconstruction: application in breeding trials. Remote Sensing 2015, 7, 4213-4232.

30. Gonzalez-Dugo, V.; Goldhamer, D.; Zarco-Tejada, P.J.; Fereres, E. Improving the precision of irrigation in a pistachio farm using an unmanned airborne thermal system. Irrigation science 2015, 33, 43-52.

31. Swain, K.C.; Thomson, S.J.; Jayasuriya, H.P. Adoption of an unmanned helicopter for low-altitude remote sensing to estimate yield and total biomass of a rice crop. Transactions of the ASABE 2010, 53, 21-27.

32. Zarco-Tejada, P.J.; González-Dugo, V.; Williams, L.; Suárez, L.; Berni, J.A.; Goldhamer, D.; Fereres, E. A PRI-based water stress index combining structural and chlorophyll effects: Assessment using diurnal narrow-band airborne imagery and the CWSI thermal index. Remote sensing of environment 2013, 138, 38-50.

33. Zhao, T.; Chen, Y.; Ray, A.; Doll, D. Quantifying almond water stress using unmanned aerial vehicles (uavs): correlation of stem water potential and higher order moments of non-normalized canopy distribution. ASME 2017 International Design Engineering Technical Conferences and Computers and Information in Engineering Conference. American Society of Mechanical Engineers, 2017, pp. V009T07A058-V009T07A058.

34. Zhao, T.; Niu, H.; de la Rosa, E.; Doll, D.; Wang, D.; Chen, Y. Tree canopy differentiation using instance-aware semantic segmentation. 2018 ASABE Annual International Meeting. American Society of Agricultural and Biological Engineers, 2018, p. 1.

35. Zhao, T.; Wang, Z.; Yang, Q.; Chen, Y. Melon yield prediction using small unmanned aerial vehicles. Autonomous Air and Ground Sensing Systems for Agricultural Optimization and Phenotyping II. International Society for Optics and Photonics, 2017, Vol. 10218, p. 1021808. 
36. Ortega-Farías, S.; Ortega-Salazar, S.; Poblete, T.; Kilic, A.; Allen, R.; Poblete-Echeverría, C.; Ahumada-Orellana, L.; Zuñiga, M.; Sepúlveda, D. Estimation of energy balance components over a drip-irrigated olive orchard using thermal and multispectral cameras placed on a helicopter-based unmanned aerial vehicle (UAV). Remote Sensing 2016, 8, 638.

37. Xia, T.; Kustas, W.P.; Anderson, M.C.; Alfieri, J.G.; Gao, F.; McKee, L.; Prueger, J.H.; Geli, H.M.; Neale, C.M.; Sanchez, L.; others. Mapping evapotranspiration with high-resolution aircraft imagery over vineyards using one-and two-source modeling schemes. Hydrology and Earth System Sciences 2016, 20, 1523.

38. Zhao, T.; Yang, Y.; Niu, H.; Wang, D.; Chen, Y. Comparing U-Net convolutional network with mask R-CNN in the performances of pomegranate tree canopy segmentation. Multispectral, Hyperspectral, and Ultraspectral Remote Sensing Technology, Techniques and Applications VII. International Society for Optics and Photonics, 2018, Vol. 10780, p. 107801J.

39. Brown, K.; Rosenberg, N.J. A Resistance Model to Predict Evapotranspiration and Its Application to a Sugar Beet Field 1. Agronomy Journal 1973, 65, 341-347.

40. Elarab, M. The application of unmanned aerial vehicle to precision agriculture: Chlorophyll, nitrogen, and evapotranspiration estimation 2016.

41. Sheng, H.; Chao, H.; Coopmans, C.; Han, J.; McKee, M.; Chen, Y. Low-cost UAV-based thermal infrared remote sensing: Platform, calibration and applications. Mechatronics and Embedded Systems and Applications (MESA), 2010 IEEE/ASME International Conference on. IEEE, 2010, pp. 38-43.

42. Ribeiro-Gomes, K.; Hernández-López, D.; Ortega, J.F.; Ballesteros, R.; Poblete, T.; Moreno, M.A. Uncooled Thermal Camera Calibration and Optimization of the Photogrammetry Process for UAV Applications in Agriculture. Sensors 2017, 17, 2173.

43. Berni, J.A.; Zarco-Tejada, P.J.; Suárez, L.; Fereres, E. Thermal and narrowband multispectral remote sensing for vegetation monitoring from an unmanned aerial vehicle. IEEE Transactions on Geoscience and Remote Sensing 2009, 47, 722-738.

44. Gade, R.; Moeslund, T.B. Thermal cameras and applications: a survey. Machine vision and applications 2014, 25, 245-262.

45. Martinelli, F.; Scalenghe, R.; Davino, S.; Panno, S.; Scuderi, G.; Ruisi, P.; Villa, P.; Stroppiana, D.; Boschetti, M.; Goulart, L.R.; others. Advanced methods of plant disease detection. A review. Agronomy for Sustainable Development 2015, 35, 1-25.

46. Zhao, T.; Stark, B.; Chen, Y.; Ray, A.; Doll, D. More reliable crop water stress quantification using small unmanned aerial systems (suas). IFAC-PapersOnLine 2016, 49, 409-414.

47. Zhao, T.; Stark, B.; Chen, Y.; Ray, A.L.; Doll, D. A detailed field study of direct correlations between ground truth crop water stress and normalized difference vegetation index (ndvi) from small unmanned aerial system (suas). 2015 International Conference on Unmanned Aircraft Systems (ICUAS). IEEE, 2015, pp. 520-525.

48. Soliman, A.; Heck, R.J.; Brenning, A.; Brown, R.; Miller, S. Remote sensing of soil moisture in vineyards using airborne and ground-based thermal inertia data. Remote Sensing 2013, 5, 3729-3748.

49. Jones, H.G.; Serraj, R.; Loveys, B.R.; Xiong, L.; Wheaton, A.; Price, A.H. Thermal infrared imaging of crop canopies for the remote diagnosis and quantification of plant responses to water stress in the field. Functional Plant Biology 2009, 36, 978-989.

50. Gowen, A.; Tiwari, B.; Cullen, P.; McDonnell, K.; O’Donnell, C. Applications of thermal imaging in food quality and safety assessment. Trends in food science E technology 2010, 21, 190-200.

51. Zhao, T.; Niu, H.; Anderson, A.; Chen, Y.; Viers, J. A detailed study on accuracy of uncooled thermal cameras by exploring the data collection workflow. Autonomous Air and Ground Sensing Systems for Agricultural Optimization and Phenotyping III. International Society for Optics and Photonics, 2018, Vol. 10664, p. 106640F.

52. Näsi, R.; Honkavaara, E.; Lyytikäinen-Saarenmaa, P.; Blomqvist, M.; Litkey, P.; Hakala, T.; Viljanen, N.; Kantola, T.; Tanhuanpää, T.; Holopainen, M. Using UAV-based photogrammetry and hyperspectral imaging for mapping bark beetle damage at tree-level. Remote Sensing 2015, 7, 15467-15493.

53. Stark, B.; Chen, Y. A framework of optimal remote sensing using small unmanned aircraft systems. 2016 12th IEEE/ASME International Conference on Mechatronic and Embedded Systems and Applications (MESA). IEEE, 2016, pp. 1-6. 
54. Harwin, S.; Lucieer, A. Assessing the accuracy of georeferenced point clouds produced via multi-view stereopsis from unmanned aerial vehicle (UAV) imagery. Remote Sensing 2012, 4, 1573-1599.

55. Lucieer, A.; Malenovskỳ, Z.; Veness, T.; Wallace, L. HyperUAS-Imaging spectroscopy from a multirotor unmanned aircraft system. Journal of Field Robotics 2014, 31, 571-590.

56. Turner, D.; Lucieer, A.; Watson, C. An automated technique for generating georectified mosaics from ultra-high resolution unmanned aerial vehicle (UAV) imagery, based on structure from motion (SfM) point clouds. Remote sensing 2012, 4, 1392-1410.

57. Wallace, L.; Lucieer, A.; Watson, C.; Turner, D. Development of a UAV-LiDAR system with application to forest inventory. Remote Sensing 2012, 4, 1519-1543.

58. Smith, G.M.; Milton, E.J. The use of the empirical line method to calibrate remotely sensed data to reflectance. International Journal of remote sensing 1999, 20, 2653-2662.

59. Kamble, B.; Kilic, A.; Hubbard, K. Estimating crop coefficients using remote sensing-based vegetation index. Remote sensing 2013, 5, 1588-1602.

60. Reyes-Gonzalez, A.; Hay, C.; Kjaersgaard, J.; Neale, C. Use of remote sensing to generate crop coefficient and estimate actual crop evapotranspiration. 2015 ASABE Annual International Meeting. American Society of Agricultural and Biological Engineers, 2015, p. 1.

61. Hunsaker, D.J.; Pinter, P.J.; Barnes, E.M.; Kimball, B.A. Estimating cotton evapotranspiration crop coefficients with a multispectral vegetation index. Irrigation science 2003, 22, 95-104.

62. Jackson, R.; Reginato, R.; Idso, S. Wheat canopy temperature: a practical tool for evaluating water requirements. Water resources research 1977, 13, 651-656.

63. SEGUIN, B.; ITIER, B. Using midday surface temperature to estimate daily evaporation from satellite thermal IR data. International Journal of Remote Sensing 1983, 4, 371-383.

64. Moran, M.; Clarke, T.; Inoue, Y.; Vidal, A. Estimating crop water deficit using the relation between surface-air temperature and spectral vegetation index. Remote sensing of environment 1994, 49, 246-263.

65. Carlson, T.N.; Gillies, R.R.; Schmugge, T.J. An interpretation of methodologies for indirect measurement of soil water content. Agricultural and forest meteorology 1995, 77, 191-205.

66. Anderson, M.; Neale, C.; Li, F.; Norman, J.; Kustas, W.; Jayanthi, H.; Chavez, J. Upscaling ground observations of vegetation water content, canopy height, and leaf area index during SMEX02 using aircraft and Landsat imagery. Remote sensing of environment 2004, 92, 447-464.

67. Carlson, T.N.; Ripley, D.A. On the relation between NDVI, fractional vegetation cover, and leaf area index. Remote sensing of Environment 1997, 62, 241-252.

68. Montibeller, Á.G. Estimating energy fluxes and evapotranspiration of corn and soybean with an unmanned aircraft system in Ames, Iowa 2017.

69. Kustas, W.P.; Norman, J.M. Evaluation of soil and vegetation heat flux predictions using a simple two-source model with radiometric temperatures for partial canopy cover. Agricultural and Forest Meteorology 1999, 94, 13-29.

70. Kustas, W.P.; Norman, J.M. A two-source energy balance approach using directional radiometric temperature observations for sparse canopy covered surfaces. Agronomy Journal 2000, 92, 847-854.

71. French, A.N.; Hunsaker, D.J.; Thorp, K.R. Remote sensing of evapotranspiration over cotton using the TSEB and METRIC energy balance models. Remote Sensing of Environment 2015, 158, 281-294.

72. Choi, M.; Kustas, W.P.; Anderson, M.C.; Allen, R.G.; Li, F.; Kjaersgaard, J.H. An intercomparison of three remote sensing-based surface energy balance algorithms over a corn and soybean production region (Iowa, US) during SMACEX. Agricultural and Forest Meteorology 2009, 149, 2082-2097.

73. Colaizzi, P.; Evett, S.; Howell, T.; Li, F.; Kustas, W.; Anderson, M. Radiation model for row crops: I. Geometric view factors and parameter optimization. Agronomy journal 2012, 104, 225-240.

74. Song, L.; Liu, S.; Kustas, W.P.; Zhou, J.; Xu, Z.; Xia, T.; Li, M. Application of remote sensing-based two-source energy balance model for mapping field surface fluxes with composite and component surface temperatures. Agricultural and forest meteorology 2016, 230, 8-19.

75. Campbell, G.S.; Norman, J.M. An introduction to environmental biophysics; Springer Science \& Business Media, 2012.

76. Shuttleworth, W.J.; Wallace, J. Evaporation from sparse crops-an energy combination theory. Quarterly Journal of the Royal Meteorological Society 1985, 111, 839-855. 
77. Priestley, C.H.B.; Taylor, R. On the assessment of surface heat flux and evaporation using large-scale parameters. Monthly weather review 1972, 100, 81-92.

78. Norman, J.; Kustas, W.; Prueger, J.; Diak, G. Surface flux estimation using radiometric temperature: A dual-temperature-difference method to minimize measurement errors. Water Resources Research 2000, $36,2263-2274$.

79. Guzinski, R.; Anderson, M.C.; Kustas, W.P.; Nieto, H.; Sandholt, I. Using a thermal-based two source energy balance model with time-differencing to estimate surface energy fluxes with day-night MODIS observations. Hydrology and Earth System Sciences 2013, 17, 2809-2825.

80. Santanello Jr, J.A.; Friedl, M.A. Diurnal covariation in soil heat flux and net radiation. Journal of Applied Meteorology 2003, 42, 851-862.

81. Guzinski, R.; Nieto, H.; Jensen, R.; Mendiguren, G. Remotely sensed land-surface energy fluxes at sub-field scale in heterogeneous agricultural landscape and coniferous plantation. Biogeosciences 2014, 11, 5021-5046.

82. Guzinski, R.; Nieto, H.; Stisen, S.; Fensholt, R. Inter-comparison of energy balance and hydrological models for land surface energy flux estimation over a whole river catchment. Hydrology and Earth System Sciences 2015, 19, 2017-2036.

83. Hunt, E.R.; Cavigelli, M.; Daughtry, C.S.; Mcmurtrey, J.E.; Walthall, C.L. Evaluation of digital photography from model aircraft for remote sensing of crop biomass and nitrogen status. Precision Agriculture 2005, $6,359-378$.

84. Gowda, P.H.; Chavez, J.L.; Colaizzi, P.D.; Evett, S.R.; Howell, T.A.; Tolk, J.A. ET mapping for agricultural water management: present status and challenges. Irrigation science 2008, 26, 223-237.

85. Bastiaanssen, W.G. SEBAL-based sensible and latent heat fluxes in the irrigated Gediz Basin, Turkey. Journal of hydrology 2000, 229, 87-100.

86. Bastiaanssen, W.G.; Ahmad, M.u.D.; Chemin, Y. Satellite surveillance of evaporative depletion across the Indus Basin. Water Resources Research 2002, 38, 9-1.

87. Ruhoff, A.L.; Paz, A.R.; Collischonn, W.; Aragao, L.E.; Rocha, H.R.; Malhi, Y.S. A MODIS-based energy balance to estimate evapotranspiration for clear-sky days in Brazilian tropical savannas. Remote Sensing 2012, 4, 703-725.

88. Singh, R.; Senay, G. Comparison of four different energy balance models for estimating evapotranspiration in the Midwestern United States. Water 2016, 8, 9.

89. Sun, Z.; Wei, B.; Su, W.; Shen, W.; Wang, C.; You, D.; Liu, Z. Evapotranspiration estimation based on the SEBAL model in the Nansi Lake Wetland of China. Mathematical and Computer Modelling 2011, 54, 1086-1092.

90. Allen, R.; Tasumi, M.; Trezza, R.; Kjaersgaard, J. METRICTM-Mapping Evapotranspiration at high resolution-Applications Manual for Landsat Satellite Imagery (Version 2.0. 4). University of Idaho 2008.

91. Walter, I.A.; Allen, R.G.; Elliott, R.; Jensen, M.; Itenfisu, D.; Mecham, B.; Howell, T.; Snyder, R.; Brown, P.; Echings, S.; others. ASCE's standardized reference evapotranspiration equation. In Watershed management and operations management 2000; 2000; pp. 1-11.

92. Bastiaanssen, W.; Noordman, E.; Pelgrum, H.; Davids, G.; Thoreson, B.; Allen, R. SEBAL model with remotely sensed data to improve water-resources management under actual field conditions. Journal of irrigation and drainage engineering 2005, 131, 85-93.

93. Jacob, F.; Olioso, A.; Gu, X.F.; Su, Z.; Seguin, B. Mapping surface fluxes using airborne visible, near infrared, thermal infrared remote sensing data and a spatialized surface energy balance model. Agronomie 2002, 22, 669-680.

94. Tasumi, M. Progress in operational estimation of regional evapotranspiration using satellite imagery. 2004.

95. Wright, J.L. New evapotranspiration crop coefficients. Proceedings of the American Society of Civil Engineers, Journal of the Irrigation and Drainage Division 1982, 108, 57-74.

96. Li, F.; Kustas, W.P.; Prueger, J.H.; Neale, C.M.; Jackson, T.J. Utility of remote sensing-based two-source energy balance model under low-and high-vegetation cover conditions. Journal of Hydrometeorology 2005, 6, 878-891.

97. Colaizzi, P.D.; Kustas, W.P.; Anderson, M.C.; Agam, N.; Tolk, J.A.; Evett, S.R.; Howell, T.A.; Gowda, P.H.; O'Shaughnessy, S.A. Two-source energy balance model estimates of evapotranspiration using component and composite surface temperatures. Advances in water resources 2012, 50, 134-151. 
98. Fisher, J.B.; Melton, F.; Middleton, E.; Hain, C.; Anderson, M.; Allen, R.; McCabe, M.F.; Hook, S.; Baldocchi, D.; Townsend, P.A.; others. The future of evapotranspiration: Global requirements for ecosystem functioning, carbon and climate feedbacks, agricultural management, and water resources. Water Resources Research 2017, 53, 2618-2626. 